\title{
Effects of Vitamin E Deficiency on the Functions of Splenic Lymphocytes and Alveolar Macrophages
}

\author{
Satoru Moriguchi, ${ }^{*}$ Naomichi KobaYashi, and Yasuo Kishino ${ }^{1}$ \\ Department of Nutrition, School of Medicine, The University of Tokushima, \\ Tokushima 770, Japan
}

(Received April 20, 1989)

\begin{abstract}
Summary This study has been done to determine the effect of vitamin E deficiency on the functions of splenic lymphocytes and alveolar macrophages (AM) in rats. Vitamin E deficiency did not cause any changes of body weight, spleen and thymus weights, and numbers of splenocytes and AM compared with those of control rats. And also, we could not find any significant changes of lymphocyte responses to mitogens (PHA, Con A, and LPS) and natural killer cell (NK) activity except for AM function in vitamin E-deficient rats. In vitamin E-deficient rats, AM showed a higher phagocytosis than that of control rats. After in vitro treatment with a macrophage-activating factor (MAF) for $4 \mathrm{~h}$ at $37^{\circ} \mathrm{C}$, AM from control rats showed a greater enhancement $(167 \%)$ of phagocytic activity compared with that of AM from vitamin E-deficient rats. When the effect of MAF prepared from splenic lymphocytes of rats from control or vitamin E-deficient rats on phagocytosis of AM was studied, MAF from control rats showed an about $150 \%$ increase of phagocytic activity in a $1 / 250$ dilution of MAF. However, MAF from vitamin E-deficient group had almost no effect on phagocytosis of AM in the same dilution of MAF as control rats. These results may suggest that vitamin $\mathrm{E}$ deficiency induces the higher phagocytic function of AM responsible for host defense in the lung, but their enhancement is not due to the activation by MAF from lymphocytes.
\end{abstract}

Key Words vitamin E deficiency, phagocytosis, alveolar macrophages, mitogen response, macrophage-activating factor

Vitamin $\mathrm{E}$ is thought to act as an important antioxidant in cellular membranes and as a free radical scavenger by blocking the peroxidation of polyunsaturated fatty acids (PUFA) $(1,2)$. Clinically, it has been known that vitamin E deficiency may cause edema and hemolytic anemia in premature infants $(3,4)$. In addition, it has been suggested that vitamin $\mathrm{E}$ also modulates the immune responses. Tengerdy

1 森口 覚, 小林直道, 岸野泰雄

* To whom correspondence should be addressed. 
et al. have reported that dietary supplementation with vitamin $\mathrm{E}$ leads to enhanced humoral immune responses and increases resistance to bacterial infection in mice and chickens $(5,6)$. Tanaka et al. found that dietary supplementation of vitamin $\mathrm{E}$ induced the enhancement of helper T-cell activity in mice (7). Haber and Wissler (8) have reported that addition of vitamin $\mathrm{E}$ to control diet inhibits carcinogenesis induced by methylcholanthrene. Recently, Yasunaga et al. (9) and Bendich et al. (10) have studied on optimum dosage of vitamin $\mathrm{E}$ to induce maximum enhancement of lymphocyte proliferation with mitogens in mice. On the other hand, there are also many reports regarding vitamin E deficiency and immune responses. Sheffy and Schultz (11) found that lymphoproliferative responses with mitogens such as concanavalin A (Con A), phytohemagglutinin (PHA), and pokeweed mitogen (PWM) were depressed in cells from vitamin E-deficient dogs. Langweiler et al. (12) have reported that sera from vitamin E-deficient dogs contain a factor capable of greatly suppressing mitogen-induced blastogenesis. A less-defined effect of vitamin E deficiency, however, is in the functions of natural killer cells and alveolar macrophages (AM), which is the focus of the present report.

\section{EXPERIMENTAL METHODS}

Animals and diets. Specific pathogen-free, inbred F344 rats, 4 to 5 weeks old, weighing about $70 \mathrm{~g}$, were obtained from Shizuoka Agricultural Cooperative Association for Laboratory Animals (Shizuoka, Japan). The rats were randomly divided into two dietary groups. Each group consisted of 10 rats, respectively. They

Table 1. Composition of vitamin E-free diet. ${ }^{a}$

\begin{tabular}{lc}
\hline Ingredients & Concentration (\%) \\
\hline Cornstarch & 36 \\
Vitamin-free casein & 25 \\
Alpha wheatstarch & 10 \\
Powdered filter paper & 8 \\
Stripped corn oil & 8 \\
Mineral mixture & 6 \\
Granulated sugar $^{\mathrm{b}}$ & 5 \\
Vitamin mixture $^{\mathrm{c}}$ & 2 \\
\hline
\end{tabular}

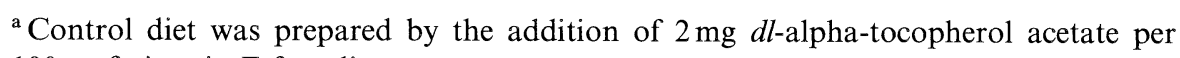
$100 \mathrm{~g}$ of vitamin $\mathrm{E}$ free diet.

${ }^{\mathrm{b}}$ The mineral mixture had the following composition $(\mathrm{mg} / 100 \mathrm{~g}$ of mixture): $\mathrm{K}, 420$; $\mathrm{P}$, 990; Na, 250; Mg, 74.9; Fe, 27.0; Zn, 5.1; Mn, 2.2; Cu, 0.57; I, 0.46.

${ }^{\mathrm{c}}$ The vitamin mixture had the following composition $(\mathrm{mg} / 100 \mathrm{~g}$ of mixture): vitamin $\mathrm{A}$, $1,000 \mathrm{IU}$; vitamin $\mathrm{D}_{3}, 200 \mathrm{IU}$; vitamin $\mathrm{B}_{1}, 2.4$; vitamin $\mathrm{B}_{2}, 8.0$; vitamin $\mathrm{B}_{6}, 1.6$; vitamin $\mathrm{B}_{12}, 0.001$; vitamin $\mathrm{C}, 60.0$; vitamin $\mathrm{K}_{3}, 10.4$; biotin, 0.04 ; folic acid, 0.4; Ca-pantothenate, 10.0; P-aminobenzoic acid, 10.0; inositol, 12.0; niacin, 12.0; choline-chloride, 400.0 . 
were housed individually in an air-conditioned room at $22 \pm 2{ }^{\circ} \mathrm{C}$ and given isoenergetic diets (Table 1) with or without vitamin $\mathrm{E}$, and water ad libitum. Body weight and food intake were measured daily. Animals of each group were killed after 4 months.

Spleen and thymus. Spleen and thymus were removed, and their weights were measured. Then, they were minced with scissors and passed through stainless steel mesh. Numbers of their lymphocytes were counted microscopically.

Macrophage-activating factor $(M A F)$. Spleens from rats of control or vitamin E-deficient group were aseptically removed and minced, and suspensions of their lymphocytes were harvested by being passed through a stainless steel mesh in medium. Then, they were adjusted to $10 \times 10^{6}$ cells $/ \mathrm{ml}$ and incubated in vitro with $100 \mu \mathrm{g} / \mathrm{ml}$ ConA Sepharose for $48 \mathrm{~h}$. After the supernatants were filtered through a $0.22 \mu \mathrm{m}$ millipore membrane, their dilutions with medium were incubated with AM from rats fed on stock diet. The production of MAF by splenic lymphocytes of control or vitamin E-deficient rats was investigated by using the phagocytic ability of AM as an index.

Preparation and culture of $A M$. AM were collected aseptically by tracheopulmonary lavage as reported previously(13). Briefly, the rats were anesthetized by pentobarbital sodium and exsanguinated. The chest cavity was opened, and the trachea was cannulated. The lungs were washed with $5 \mathrm{ml}$ of physiological saline at $37^{\circ} \mathrm{C}$, which was repeated to obtain a total volume of $50 \mathrm{ml}$ of lavaged fluid per rat. The number and viability of nucleated cells were determined by trypan blue staining. More than $95 \%$ of lavaged cells were AM and positive for nonspecific esterase staining. The AM were collected by centrifugation and layered on wells of a Multiwell plate (Falcon Plastic, Oxnard, Calif.) containing $1 \mathrm{ml}$ of RPMI 1640 medium with 5\% fetal bovine serum (FBS) (Nissui Seiyaku, Tokyo). After $60 \mathrm{~min}$, nonadherent cells including neutrophils were removed by washing the plates with medium. The AM were then incubated in the medium or medium containing diluted MAF for $4 \mathrm{~h}$ at $37^{\circ} \mathrm{C}$ under $5 \% \mathrm{CO}_{2}$ in air.

Phagocytosis assay. Sheep red blood cells (SRBC) were maintained in Alsever's solution (Grand Island Biological, Grand Island, N.Y.) and $4{ }^{\circ} \mathrm{C}$. Opsonization was accomplished by incubating $20 \mathrm{ml}$ of a $2 \% \mathrm{v} / \mathrm{v}$ SRBC suspension with $0.2 \mathrm{ml}$ of rat anti-SRBC antiserum (heat-inactivated) for $60 \mathrm{~min}$ at $37^{\circ} \mathrm{C}$. The antiserum was prepared by injecting i.p. $0.2 \mathrm{ml}$ of washed SRBC to rats at weekly intervals (14). The suspension was centrifuged and the supernatant fraction was discarded. Radioactive labeling of the opsonized SRBC was accomplished by incubation with $200 \mu \mathrm{Ci}$ of $\mathrm{Na}_{2}\left[{ }^{51} \mathrm{Cr}\right] \mathrm{O}_{4}(1 \mathrm{mCi} / \mathrm{ml})$ for $1 \mathrm{~h}$ at $37^{\circ} \mathrm{C}$. The opsonized SRBC were then washed three times with RPMI 1640 medium to remove excess ${ }^{51} \mathrm{Cr}$, and the final volume was adjusted to give a $0.6 \%$ suspension of SRBC. AM, $2 \times 10^{5}$ cells $/ \mathrm{ml}$, were incubated in RPMI 1640 medium containing 5\% FBS and diluted MAF for $4 \mathrm{~h}$, and then opsonized SRBC labeled with ${ }^{51} \mathrm{Cr}$ were added. After $2 \mathrm{~h}$ at $37^{\circ} \mathrm{C}$, the cultures were rinsed once with distilled water to lyse nonphagocytosed SRBC and then washed twice with $0.1 \mathrm{M}$ phosphate buffer, $\mathrm{pH}$ 
7.2. All remaining cells were lysed with $0.1 \mathrm{~N} \mathrm{NaOH}$, and the radioactivity of the lysate was measured in a gamma counter.

Assay of natural killer cell (NK) activity. Splenocytes from each group were assayed for NK activity as described previously (15). Percent of lysis was calculated as follows:

$$
\% \text { lysis }=\frac{\text { experimental }{ }^{51} \mathrm{Cr} \text { release }- \text { spontaneous }{ }^{51} \mathrm{Cr} \text { release }}{\text { maximum }{ }^{51} \mathrm{Cr} \text { release }- \text { spontaneous }{ }^{51} \mathrm{Cr} \text { release }} \times 100 .
$$

Spontaneous ${ }^{51} \mathrm{Cr}$ release was determined from target cell culture incubated with medium alone. Maximum ${ }^{51} \mathrm{Cr}$ release was determined by dissolving all tumor cells with $0.1 \mathrm{ml}$ of $1 \mathrm{~N} \mathrm{NaOH}$.

Mitogenesis of splenocytes. Splenic T- and B-lymphocyte responses to mitogens such as Con A, PHA, and lipopolysaccharide (LPS) from Escherichia coli were determined as reported previously (16).

Briefly, single cell suspensions of $1 \times 10^{6}$ cells $/ \mathrm{ml}$ were prepared in RPMI 1640 medium supplemented with $25 \mathrm{~mm}$ 4-(2-hydroxyethyl)-1-piperazineethanesulfonic acid (HEPES) buffer, $100 \mathrm{u} / \mathrm{ml}$ penicillin, $100 \mu \mathrm{g} / \mathrm{ml}$ streptomycin, and $50 \mu \mathrm{mol} / \mathrm{ml}$ 2-mercaptoethanol. Splenocytes with or without mitogens were plated in 96-well microtiter plates, incubated in $5 \% \mathrm{CO}_{2}$ incubator at $37^{\circ} \mathrm{C}$ for $72 \mathrm{~h}$, and then pulsed with $1.0 \mu \mathrm{Ci}\left[{ }^{3} \mathrm{H}\right]$ thymidine (specific activity $25 \mathrm{Ci} / \mathrm{mmol}$, New England Nuclear). After $24 \mathrm{~h}$, they were harvested. Radioactivity was measured by a liquid scintillation counter, and data are presented as counts per min (cpm). Some of the splenocytes were immediately pulsed with $\left[{ }^{3} \mathrm{H}\right]$ thymidine after isolation in single cells.

Blood samples. In this experiment, heparinized blood was collected from inferior vena cava of rats fed on control or vitamin E-deficient diet. Plasma vitamin E level was determined by high-performance liquid chromatography (HPLC) (17). Some blood was also used for the determination of the percentage of red blood cell hemolysis by hydrogen peroxide $\left(\mathrm{H}_{2} \mathrm{O}_{2}\right)(18)$.

Statistical analysis. Results were analyzed for statistical significance by the Student's $t$-test (two-tailed).

\section{RESULTS}

\section{Growth and diet consumption}

Male F344 rats, 4 to 5 weeks old, were fed on ad libitum control or vitamin E-deficient diet for 4 months. The diet consumption of each group was similar. There was no significant difference in body weights (control group, $339 \pm 12.2 \mathrm{~g}$; vitamin E-deficient group, $334 \pm 10.4 \mathrm{~g}$ ) at 4 months after the onset of experiment. The weights of thymus and spleen were also not significantly different in both groups $(0.83 \pm 0.05 \mathrm{~g}$ and $0.24 \pm 0.01 \mathrm{~g}$ in control group; $0.77 \pm 0.05 \mathrm{~g}$ and $0.20 \pm 0.02 \mathrm{~g}$ in vitamin E deficient group, respectively). And also, there was no significant difference in numbers of splenocytes, thymocytes, and AM between control and vitamin E-deficient groups. 
Table 2. Alpha-tocopherol level in plasma.

\begin{tabular}{ccc}
\hline & Control & VE deficient \\
\cline { 2 - 3 } No. & & $(\mu \mathrm{g} / \mathrm{ml})$ \\
& & \\
\hline 1 & 2.71 & 0.33 \\
3 & 2.82 & 0.29 \\
4 & 2.52 & 0.30 \\
5 & 2.80 & 0.26 \\
6 & 2.44 & 0.34 \\
7 & 2.66 & 0.21 \\
8 & 2.30 & 0.28 \\
9 & 2.61 & 0.31 \\
10 & 2.53 & 0.27 \\
Means \pm SD & 2.36 & 0.32 \\
\hline
\end{tabular}

${ }^{\text {a }}$ Significantly different from control rats $(p<0.001)$.

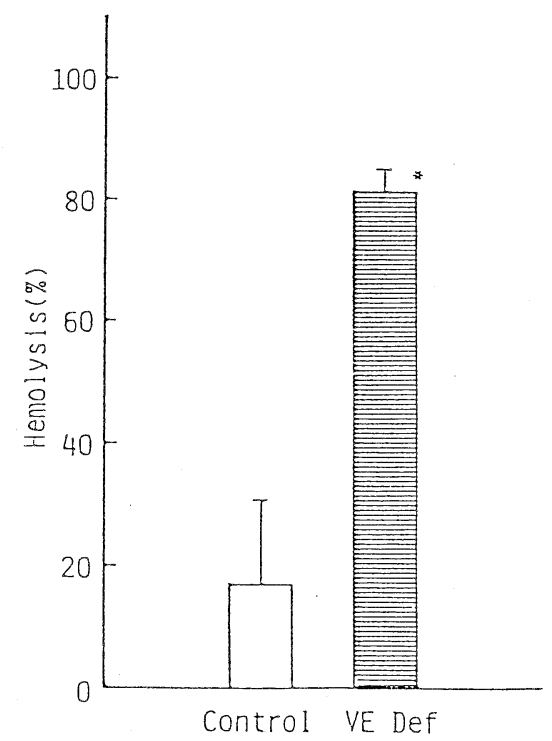

Fig. 1. Percent hemolysis of red blood cells (RBC) from control or vitamin E-deficient rats by hydrogen peroxide. After $\mathrm{RBC}$ were treated with saline or $0.25 \% \mathrm{H}_{2} \mathrm{O}_{2}$ for $3 \mathrm{~h}$ at $37^{\circ} \mathrm{C}$ and then centrifuged at $3,000 \mathrm{rpm}$ for $10 \mathrm{~min}$, their absorbancies were measured by photoelectric meter. Each result is a percent to that of maximum hemolysis destroying RBC completely with distilled water. Each value represents the mean \pm SD from 10 rats. ${ }^{*}$ Significantly different from control rats $(p<0.001)$. 
Plasma vitamin E level and percent peroxidative hemolysis

The plasma vitamin E level was significantly lower in vitamin E-deficient group compared with that of control group (Table 2). And red blood cells from vitamin E-deficient rats showed a remarkable hemolysis (about $80 \%$ ) by incubation with $0.05 \% \mathrm{H}_{2} \mathrm{O}_{2}$ compared with that of control rats (18\%) (Fig. 1). Both results suggested that rats fed on vitamin E-deficient diet were obviously in the state of vitamin $\mathrm{E}$ deficiency even though the retardation of growth and the decreases of spleen and thymus weights were not shown in this experiment.

Mitogenesis and NK activity in splenocytes

The lymphocyte transformation assay was performed with isolated rat splenocytes from control and vitamin E-deficient groups. As shown in Fig. 2, there were no significant differences in the mitogenic responses stimulated by PHA, ConA, and LPS between control and vitamin E-deficient groups. NK activity was a little lower in vitamin E-deficient group compared with that of control group, but its difference was not significant (Fig. 3).

\section{Phagocytosis of opsonized SRBC by AM}

AM obtained from rats given control or vitamin E-deficient diet for 4 months were incubated in vitro for $4 \mathrm{~h}$ in medium only or in medium containing MAF

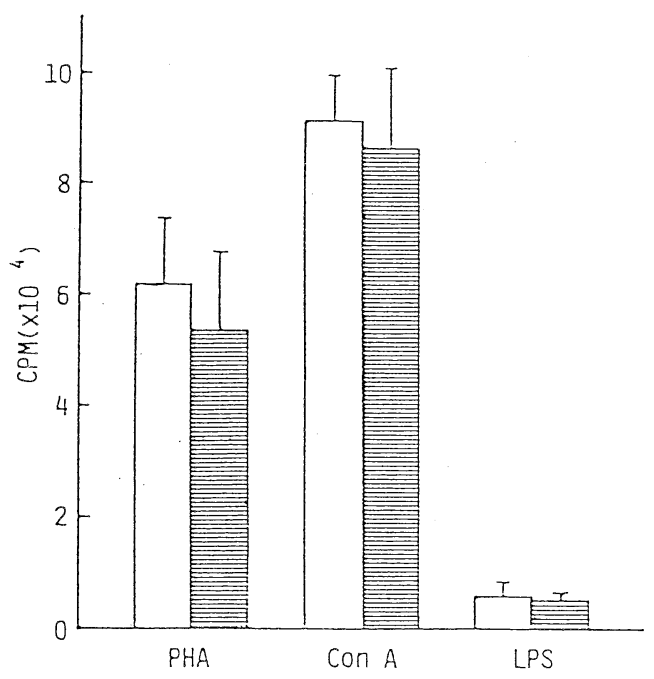

Fig. 2. Effect of vitamin $\mathrm{E}$ deficiency on proliferative response of rat splenic lymphocytes. After splenic lymphocytes were isolated from spleens of 10 control $(\square)$ or 10 vitamin E-deficient ( $\square$ ) rats, they were cultured with phytohemagglutinin (PHA), concanavalin A (Con A), or lipopolysaccharide (LPS) for 4 days. At 17 to $24 \mathrm{~h}$ before termination of cultures, $50 \mu 1$ of $\left[{ }^{3} \mathrm{H}\right]$ thymidine $(20 \mu \mathrm{Ci} / \mathrm{ml})$ was added. Each value is the mean $\pm \mathrm{SD}$ for triplicate cultures of a representative experiment. 


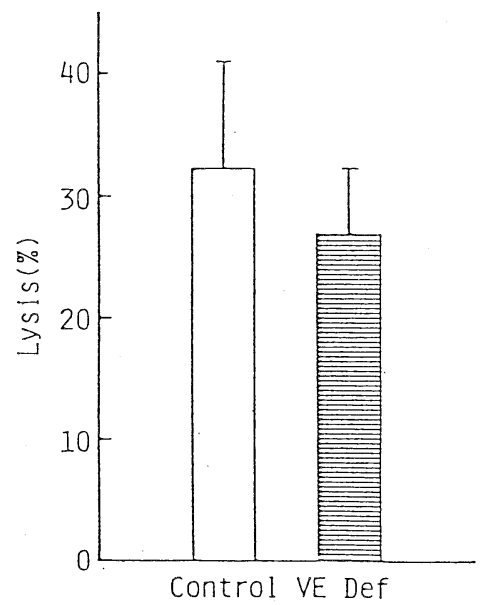

Fig. 3. Effect of vitamin E deficiency on natural killer cell (NK) activity. After splenic lymphocytes were isolated from spleens of 10 control $(\square)$ or 10 vitamin E-deficient ( $)$ rats, their NK activities were measured by ${ }^{51} \mathrm{Cr}$-release assay. The ratio of lymphocytes (effector cell) and YAC-1 (target cell) was $100: 1$. Each value represents the mean $\pm \mathrm{SD}$ for triplicate cultures of a representative experiment.

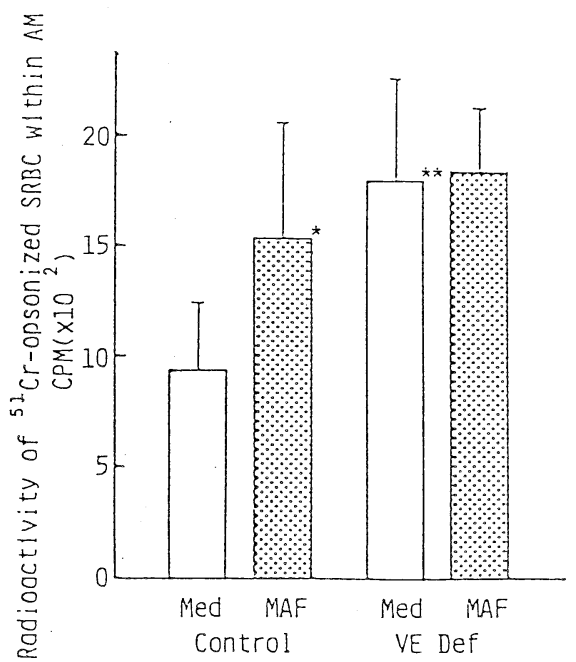

Fig. 4. Phagocytosis of ${ }^{51} \mathrm{Cr}$-labeled opsonized sheep red blood cells (SRBC) by alveolar macrophages (AM) of rats fed on control or vitamin E-deficient diet. First, $2 \times 10^{5} \mathrm{AM}$ were preincubated for $4 \mathrm{~h}$ in medium only (RPMI 1640 with $5 \%$ fetal bovine serum) or in medium with macrophage-activating factor (MAF, 1/162 dilution). Then, they were incubated with ${ }^{51} \mathrm{Cr}$-labeled opsonized SRBC for $2 \mathrm{~h}$. Each value is the mean \pm SD for triplicate cultures. ${ }^{*}$ Significantly different from cultures with medium only $(p<0.05)$. ${ }^{* *}$ Significantly different from cultures with medium only in control rats $(p<0.01)$. 
(1/162 dilution). Then, AM monolayers were washed, and their abilities to phagocytose opsonized SRBC were examined. Without any in vitro activations, AM from rats fed on vitamin E-deficient diet showed about 2 times higher phagocytic

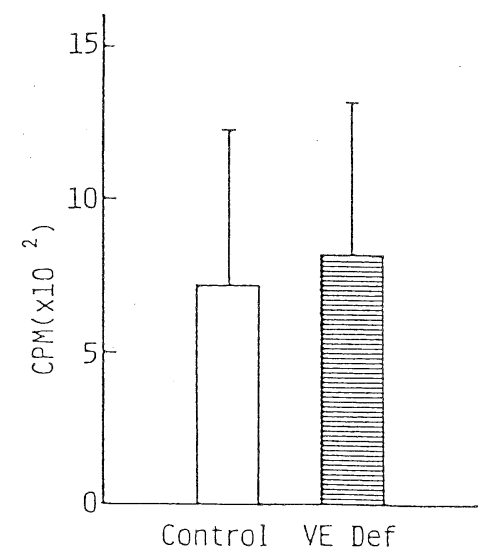

Fig. 5. Proliferation of splenic lymphocytes from rats fed on control ( $\square$ ) or vitamin E-deficient ( $\square$ ) diet for 4 months. Splenocytes were suspended in medium at $1 \times 10^{6}$ cells $/ \mathrm{ml}$. Then, $0.1 \mathrm{ml}$ of cell suspension was cultured with $0.1 \mathrm{ml}$ of medium, and $50 \mu \mathrm{lof}\left[{ }^{3} \mathrm{H}\right]$ thymidine $(20 \mu \mathrm{Ci} / \mathrm{ml})$ was added. After $20 \mathrm{~h}$, the cells were harvested and their radioactivities were counted. Results are means \pm SD for triplicate cultures.

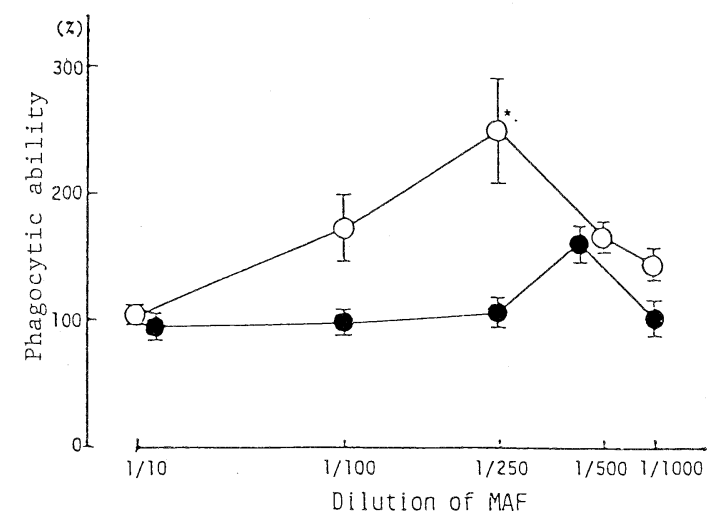

Fig. 6. Effect of vitamin E deficiency on the production of MAF from rat splenocytes. MAF was prepared from splenic lymphocytes of rats fed on control $(O)$ or vitamin E-deficient (๑) diet for 4 months. The production of MAF by splenic lymphocytes of control or vitamin E-deficient rats was investigated by using the phagocytic ability to ingest ${ }^{51} \mathrm{Cr}$-opsonized SRBC by AM from rats fed on stock diet as an index. Each value is the mean \pm SD for triplicate cultures. Percent phagocytic ability was calculated by assigning $100 \%$ to phagocytic activity of AM incubated with medium only and comparing to phagocytic activity of AM incubated with some dilutions of MAF. 
activities than those of control rats (Fig. 4). On the other hand, AM from control rats became more phagocytic after in vitro treatment with MAF for $4 \mathrm{~h}$, while AM from vitamin E-deficient rats did not respond to MAF.

\section{Uptake of $\left[{ }^{3} \mathrm{H}\right]$ thymidine by splenocytes}

Splenocytes were immediately pulsed with $\left[{ }^{3} \mathrm{H}\right]$ thymidine. Splenocytes from both control and vitamin E-deficient groups showed similar incorporations of $\left[{ }^{3} \mathrm{H}\right]$ thymidine (Fig. 5).

Production of MAF by splenocytes of rats fed on control or vitamin E-deficient diet

The phagocytic ability to ingest ${ }^{51} \mathrm{Cr}$-opsonized SRBC by AM was measured after incubation with MAF prepared from splenocytes of control or vitamin E-deficient rats for $4 \mathrm{~h}$. MAF from control rats enhanced phagocytic activity of AM, which reached a maximum $(250 \%)$ at the dilution in a ratio of $1: 250$. On the other hand, MAF from vitamin E-deficient rats induced higher phagocytic activity at the dilution in a ratio of 1:500. However, its increase was much less than that induced by MAF prepared from splenocytes of control rats (Fig. 6).

\section{DISCUSSION}

Rats fed on vitamin E-deficient diet for 4 months showed no changes in body, thymus or spleen weight, and number of splenocytes, thymocytes, or AM compared with those of control rats. Eskew et al. (19) have reported that rats fed on diet deficient in both vitamin $\mathrm{E}$ and selenium decreased their food intakes and began to lose weight by the fourth week. However, they could not also find any changes of food intake and weight gain in rats fed on vitamin E-deficient diet, in agreement with our results. There are very few reports on the decreased weight of thymus or spleen following vitamin E deficiency. Gabriel et al.(20) showed significant splenomegaly on vitamin E-deficient diet rather than the decreased weight of spleen. Our results also showed no significant differences in numbers of splenocytes, thymocytes, and AM between control and vitamin E-deficient rats. We could not find any effects of vitamin $\mathrm{E}$ deficiency on nutritional parameters in this experiment as stated above. But it was obvious that those rats were in vitamin E-deficient state, since vitamin $\mathrm{E}$ level in their plasma decreased (Table 2) and percent hemolysis of erythrocytes by hydrogen peroxide remarkably increased in rats fed on vitamin E-deficient diet (Fig. 1).

Although there is extensive data regarding the supplemental effects of vitamin $\mathrm{E}$, there are relatively few studies on vitamin $\mathrm{E}$ deficiency and immune functions. In general, vitamin $\mathrm{E}$ deficiency depresses lymphocyte blastogenesis to mitogens such as PHA, ConA, and PWM in dogs $(11,21)$, decreases NK activity in mice (22), and impairs chemotaxis and ingestion of complement $\mathrm{C}_{3}$-coated particle in neutrophils or peritoneal macrophages in rats (23). In this experiment, most of the immune functions tested here were not affected by vitamin E deficiency. NK activity 
as shown in Fig. 3 slightly decreased in vitamin E-deficient rats, but it was not significantly different from that of control rats. Phagocytic function of AM only showed the marked change following vitamin E deficiency as shown in Fig. 4. Those AM revealed about 2 times higher phagocytosis of ${ }^{51} \mathrm{Cr}$-opsonized $\mathrm{SRBC}$ than that of control rats. Furthermore, those AM of vitamin E-deficient rats did not respond to the in vitro treatment with MAF. In our previous studies, similar results have been found in protein-deficient (13) and pyridoxine-deficient (24) rats. These results suggested that AM from rats fed on vitamin E-deficient diet appeared to be already in the activated state, which was probably induced via MAF-like materials produced from the activated lymphocytes. But we failed to find that splenocytes isolated from rats fed on vitamin E-deficient diet showed significantly higher incorporation of $\left[{ }^{3} \mathrm{H}\right]$ thymidine than those of control rats. Furthermore, as shown in Fig. 6, MAF production from splenocytes activated in vitro with Con A-Sepharose beads also decreased in vitamin E-deficient rats. These phenomena suggest that the higher phagocytic activity of AM from rats fed on vitamin E-deficient diet is not induced via MAF from activated lymphocytes.

If so, it raises a question as to how such an enhanced phagocytosis of AM was induced in vitamin E-deficient rats. Nathan(25) has reported that excess production of active oxygen species, such as hydrogen peroxide, hydroxyl radical or other oxygen intermediated, is involved in mediating cytotoxic reactions. Thus, the increased function of AM in rats as shown in Fig. 4 may be attributable to vitamin E deficiency.

On the other hand, Sharp and Colston (26) demonstrated the presence of highly activated macrophages in nude mice. It was considered that the hyperactivity seen in the macrophages of nude mice resulted from a lack of T cell-mediated suppression. And many reports (27-29) have shown that vitamin E deficiency should cause immunodepression including $\mathrm{T}$ - and B-lymphocyte responses. In this experiment there was no significant difference in mitogen responses of rat splenocytes between control and vitamin E-deficient rats as shown in Fig. 2. This suggests that vitamin E deficiency does not inhibit the maturation of T- and B-cells, and the increased phagocytic activity of AM following vitamin E deficiency was not induced by the suppression of $\mathrm{T}$ cell maturation.

It is well known that vitamin $\mathrm{E}$ is an essential constituent of all the membranes found in cells including mitochondrial and nuclear mambrane (30). If vitamin $\mathrm{E}$ is deficient in the diet, it would cause some changes in membranes of AM. Such changes may result in inducing higher sensitivity of AM to MAF and showing higher phagocytic ability of AM.

In conclusion, vitamin E deficiency affected AM function only, even though most of the nutritional and immunological parameters did not show any significant changes. To elucidate the mechanism of AM activition by vitamin E deficiency needs further investigation. 


\section{REFERENCES}

1) Oski, F. A. (1977): Metabolism and physiologic roles of vitamin E. Hosp. Pract., 12, 79-85.

2) Tappel, A. L. (1972): Vitamin E and free radical peroxidation of lipids. Ann. N. Y. Acad. Sci., 203, 12-28.

3) Oski, F. A., and Barness, L. A. (1986): Hemolytic anemia in vitamin E deficiency. Am. J. Clin. Nutr., 21, 45-50.

4) Lo, S. S., Frank, D., and Hitzig, W. H. (1973): Vitamin E and haemolytic anaemia in premature infants. Arch. Dis. Child., 48, 360-365.

5) Tengerdy, R. P., Heinzerling, R. H., and Nockels, C. F. (1972): The effect of vitamin $\mathrm{E}$ on the immune response of hypoxic and normal chickens. Infect. Immun. 5, 987-989.

6) Tengerdy, R. P., Heinzerling, R. H., Brown, G. L., and Mathias, M. M. (1973): Enhancement of humoral immune response by vitamin E. Int. Arch. Allergy Appl. Immunol., 44, 221-232.

7) Tanaka, J., Fujiwara, H., and Torisu, M. (1979): Vitamin E and immune response. I. Enhancement of helper $\mathrm{T}$ cell activity by dietary supplementation of vitamin $\mathrm{E}$ in mice. Immunology, 38, 727-734.

8) Haber, S. L., and Wissler, R. W. (1962): Effect of vitamin E on carcinogenicity of methylcholanthrene. Proc. Soc. Exp. Biol. Med., 111, 774-775.

9) Yasunaga, T., Kato, H., Ohgaki, K., Inamoto, T., and Hikasa, Y. (1982): Effect of vitamin $\mathrm{E}$ as an immunopotentiation agent for mice at optimal dosage and its toxicity at high dosage. $J$. Nutr., 112, 1075-1084.

10) Bendich, A., Barbriel, E., and Machlin, L. J. (1986): Dietary vitamin E requirement for optimum immune responses in rats. J. Nutr., 116, 675-681.

11) Sheffy, B. E., and Schultz, R. D. (1979): Influence of vitamin E and selenium on immune response mechanisms. Fed. Proc., 38, 2139-2143.

12) Langweiler, M., Schultz, R. D., and Sheffy, B. E. (1981): Effect of vitamin E deficiency on the proliferative response of caine lymphocytes. Am. J. Vet. Res., 42, 1681-1685.

13) Moriguchi, S., Sone, S., and Kishino, Y. (1983): Changes of alveolar macrophages in protein-deficient rats. J. Nutr., 113, 40-46.

14) Sone, S., and Fidler, I. J. (1981): Activation of rat alveolar macrophages to the tumoricidal state in the presence of progressively growing pulmonary metastasis. Cancer Res., 41, 2401-2406.

15) Moriguchi, S., Werner, L., and Watson, R. R. (1985): High dietary vitamin A (retinyl palmitate) and cellular immune functions in mice. Immunology, 56, 169-177.

16) Moriguchi, S., Jackson, J. C., and Watson, R. R. (1985): Effects of retinoids on human lymphocyte functions in vitro. Hum. Toxicol., 4, 365-378.

17) Kato, H., Tanimura, H., and Hikasa, Y. (1981): Determination of serum tocopherols by high-performance liquid chromatography. Arch. Jpn. Chir., 50, 740-746.

$18)$ Gordon, H. H., Nitowsky, H. M., and Cornblath, M. (1955): Studies on tocopherol deficiency in infants and children. I. Hemolysis of erythrocytes in hydrogen peroxide. Am. J. Dis. Child., 91, 669-681.

19) Eskew, M. L., Scholz, R. W., Reddy, C. C., Todhunter, D. A., and Zarkower, A. (1985): Effects of vitamin $\mathrm{E}$ and selenium deficiency on rat immune function. Immuno$\log y$, 54, 173-180.

20) Gabriel, E., Bendich, A., and Machlin, L. J. (1984): Strain differences in testes degeneration, myopathy, and the lymphocyte mitogen response in vitamin E-deficient 
rats. Proc. Soc. Exp. Biol. Med., 176, 378-383.

21) Sheffy, B. E., and Schultz, R. D. (1978): Nutrition and the immune response. Cornell Vet., 68, Supple. 7, 48-61.

22) Meeker, H. C., Eskew, M. L., Scheuchenzuber, W., Scholz, R. W., and Zarkower, A. (1985): Antioxidant effects of cell-mediated immunity. J. Leukocyte Biol., 38, 451-458.

23) Harris, R. E., Boxer, L. A., and Baehner, R. L. (1978): Abnormal membrane function of phagocytes from vitamin E deficient rats. Pediatr. Res., 12, 464 (Abstract).

24) Moriguchi, S., and Kishino, Y. (1984): Phagocytosis of alveolar macrophages of pyridoxine-deficient rats. $J$. Nutr., 114, 888-893.

25) Nathan, C. F. (1982): Secretion of oxygen intermediates: role in effector functions of activated macrophages. Fed. Proc., 41, 2206-2211.

26) Sharp, A. K., and Colston, M. J. (1984): Elevated macrophage activity in nude mice. Expl. Cell Biol., 52, 44-47.

27) Bendich, A., Gabriel, E., and Machlin, L. J. (1983): Effect of dietary level of vitamin $\mathrm{E}$ on the immune system of the spontaneously hypertensive (SHR) and normotensive Wistar Kyoto (WKY) rat. J. Nutr., 113, 1920-1926.

28) Gillis, S., Ferm, M. M., Ou, W., and Smith, K. A. (1978): T cell growth factor: Parameters of production and a quantitative microassay for activity. J. Immunol., 120, 2027-2032.

29) Corwin, L. M., Gordon, R. K., and Sholoss, J. (1981): Studies of the mode of action of vitamin $\mathrm{E}$ in stimulating T-cell mitogenesis. Scand. J. Immunol., 14, 565-571.

30) Machlin, L. J. (1984): Vitamin E, In Handbook of Vitamins, ed. by Marcel Dekker, New York, pp. 99-145. 